\title{
Firm Exit Through Bankruptcy - The Effect of Accounting Bias on Product Market Competition*
}

\author{
Hui Chen Bjorn Jorgensen \\ The University of Colorado
}

\begin{abstract}
We analyze the effect of accounting biases on the profits of firms that compete in a Cournot product market. We find accounting biases strictly decrease firms' profits when the firms are fully equity-financed. However, different results emerge when we introduce debt into the firms' financial structures. Firms must report interim accounting signals, on which their debt covenants are based. We contrast firms' profits under an unbiased accounting system, a conservative accounting system and an aggressive accounting system. Conservative accounting system increases the likelihood of debt covenant violations and firm liquidation. Interestingly, the increased likelihood of liquidation could make the borrowing firms better off by turning the surviving firm into a monopolist that captures the entire market share. In addition, conservative accounting bias gives the banks more decision rights in liquidating or re-organizing the firms' operations, thus reducing the "excessive liquidation" problem. Absent renegotation, conservative accounting system improves the banks' payoffs.
\end{abstract}

*The authors' emails are hui.chen@colorado.edu and bjorn.jorgensen@colorado.edu, respectively. We would like to thank Tim Baldenius, Eva Labro, Jing Li, Jeremy Michels, Nathalie Moyen, and workshop participants at Carnegie Mellon University for helpful discussions and comments. 


\section{Introduction}

Most debt covenants are based on accounting information ${ }^{1}$. This fact suggests accounting is likely to play an important role when debt is present. In this paper, we demonstrate how accounting practices could influence the structure/organization of an oligopolistic product market through the debt borrowed by the competing firms. This effect arises primarily through the bank's liquidation decision, which is based on the accounting signals reported by the borrowing firms. The accounting bias contained in a firm's reported signal could cause the firm to be inappropriately liquidated (or continued), thus changing the competitive nature of the whole industry.

Prior studies have examined the impact of product market competition on accounting disclosure, the impact of product market competition on debt, and the impact of debt on accounting disclosure. However, to our knowledge, no study has looked at all of these three components together in a single setting. We thus contribute to the existing literature by showing how accounting disclosure could affect product market competition through debt. As our analyses show, this effect is non trivial. Banks' liquidation decisions can change a product market from a duopoly into a monopoly, or even completely shut down the market. Accounting reports are the information the banks use to make such liquidation decisions. Depending on the direction of accounting bias and the demand function of the market, accounting bias can lead to excessive-liquidation (or excessive-continuation) of the firms in the product market. However, the over-liquidation does not necessarily cause the debtefficiency to go down. In fact, accounting bias can actually increase the total expected payoff of the banks and borrowing firms to a level higher than that under an unbiased accounting system. Thus, the banks and the borrowing firms competing in an oligopoly may prefer an accounting regime with deliberate bias.

We investigate the effect of accounting bias on imperfect product market competition

\footnotetext{
${ }^{1}$ For example, Demerjian (2011) examines 100 randomly-selected private debt covnants, and found 96 use income statement -based information and 68 use balance sheet-based information.
} 
through debt. We analyze two firms that compete in an imperfect product market in Cournot fashion. Both firms borrow from banks to finance their operations. The firms are subject to an externally imposed accounting system that may have a conservative or aggressive bias. After the firms learn their cost information, they must provide a public report following the requirements of the accounting system. The firms' debt covenants with the banks are also based on the accounting reports. When a good signal is reported, the firm's control rights remain in the hands of the firm owner/manager. When a bad signal is reported, the firm is taken over by the creditor. A conservative accounting system thus provides the creditor with more decision rights than an aggressive accounting system by triggering debt covenant violation earlier. While the firm's owner/manager always prefers to continue the firm's operation and cannot reduce "false negative" error, the creditor can reduce "false positives" by not always terminating firms with bad reports. ${ }^{2}$

We first show that accounting bias decreases the firms' payoffs in a debt-free world. Compared to the benchmark of an unbiased accounting system, the firms' expected profits are strictly lower under the conservatively or aggressively biased accounting systems. We then proceed to a conservative setting where the firms are forced to sometimes report a bad signal when the true cost is good. The consequence of such conservative accounting bias is excessive liquidation as the firms' debt covenants are easily violated. However, the firms may actually benefit from this increased frequency of convenant violation. In an imperfect product market, one firm being shut down means the market share is transferred to the surviving rival. Thus, it is possible for the remaining firm to earn higher profit due to the change in the market structure. We show when the potential increase in firm profits due to the market structural change outweighs the potential loss of profits due to excessive liquidation, the firms are actually better off under conservative accounting system.

Further, the banks take over the control rights of the firms when a covenant violation

\footnotetext{
${ }^{2}$ We consider the borrower's potential bankruptcy risk as the primary concern of the bank, thus false negative refers to the error when a firm is reported as good but is actually a bad type; while false positive refers to the error when a firm is reported as bad but is actually a good type.
} 
is triggered by bad cost reports. The banks then have the option of immediately liquidating the firms, or re-organizing the firms and letting them continue operations. ${ }^{3}$ If the banks randomly liquidate the firms with bad cost reports, there would be a Pareto improvement to all players payoffs. Since we assume a zero-profit constraint on the banks, the gains from the random liquidation would be passed over to the firms, thus lowering the firms' interest rates and increasing their expected profits.

Under an aggressive accounting system, the firms' payoffs are generally lower than that under an unbiased accounting system. With aggressive accounting bias in the cost report, the debt covenant is less likely to be violated. On the contrary, there is a higher likelihood of firms that should have been liquidated being allowed to continue. Thus, the firms' expected profits are generally lower due to more intense competition.

The intuition behind accounting conservatism leading to possible higher payoffs lies in the conservative bias' role in softening Cournot competition. With a conservative accounting system, the competing firms are sometimes forced to abandon the market through bank liquidation. The surviving firm then gets to capture the entire market share. The banks thus indirectly play a role in mitigating market competition between the rival firms. Aggressive accounting system does the opposite. It exacerbates the situation by inducing fiercer competition. The players' payoffs are therefore lower.

Another interesting case arises when the same bank lends to both competing firms. In the context of Cournot competition, the bank can decide which firm to liquidate and which firm to allow to survive, when both firms report bad signals. The bank thus effectively turns the surviving firm into a monopolist, which then generates enough profit to pay back the debt. Since the bank only has decision rights when the reported signal is bad, conservatism serves to facilitate the control over the market and reduce the risk faced by the creditor. Again since the bank earns zero-profit, the extra gain from conservative accounting is passed

\footnotetext{
${ }^{3}$ In the U.S., a firm can choose to file Chapter 7 or Chapter 11 bankruptcy. With Chapter 7 bankruptcy, the firm is immediately liquidated; while with Chapter 11 bankrupcy, the firm is re-orgnized and allowed to continue with operations.
} 
onto the borrowing firms through decreased interest rate.

The setup of our model is standard. We assume the nature of the product market competition is Cournot with perfectly substitutable products. We follow Venugopalan (2001) and $\mathrm{Li}$ (2009) in characterizing accounting conservatism, which is exogenously given in the model. When the accounting system is conservative, a good signal is perfectly informative while a bad signal is noisy. When the accounting system is aggressive, a bad signal is perfectly informative while the good signal is noisy. These definitions are also consistent with the interpretation of conservatism by most empirical work such as Basu (1997). We assume perfect competition in the banking market, thus our representative bank faces a zero-profit constraint. ${ }^{4}$

We do not intend to endogenously derive the optimal level of conservatism in a single firm setting. Rather, we examine the impact of conservatism that is exogenously imposed. We also do not explain the existence of debt. The demand for debt is assumed rather than derived. Our goal in this paper is to show the presence of debt affects the interaction between accounting conservatism and firms' operating decisions in an imperfect product market setting. Conservatism provides the creditor with additional tools for reducing the lending risk associated with asymmetric information on the borrower's type; thus improves lending efficiency and reduce interest rate.

Our paper is related to three areas of research. The first area is the impact on accounting disclosure of imperfect product market competition (without the presence of debt). Several studies present related research findings in different settings. Darrough and Stoughton (1990) show threat of entry may provide firms with incentives to disclose information. Darrough (1993) examines firms' reporting behavior when engaged in Cournot or Bertrand competition. Wagonhoffer (1990) studies a firm's optimal voluntary disclosure strategy when facing a strategic market rival, and finds such disclosure may increase the firm's product price while

\footnotetext{
${ }^{4}$ The zero-profit constraint is not critical in obtaining our main results. When the banks are allowed to maximize their own payoffs, they would not transfer all extra payoff to the borrowing firms. The banks thus would demonstrate a strict preference to a conservative accounting system.
} 
simultaneously imposing a proprietary cost on itself. Bagnoli and Watts (2010) also examine how firms bias their accounting reports when competing in a Cournot fashion and the effect of accounting bias on the firms' production decision.

A second area of literature focuses on capital structure and imperfect product market competition. Brander and Lewis (1986) show a firm competing in an oligopolistic market behaves more aggressively when it has higher debt, thus the whole industry settles on an equilibrium with the excessive debt in the firms' financial structure. Clayton and Jorgensen (2005) examine the strategic effect of cross-holding of competing firms on their product market competition. Hughes and Kao (1998), Hughes and Williams (2008) analyze how financial structure can be used as a commitment device in oligopolistic competition.

A third area of research our paper relates to is how debt contracting affects accounting behavior. Specifically, there is a recent stream of literature focusing on debt contract efficiency and accounting conservatism. Venugopalan (2004) models accounting conservatism as a systematic bias to put more weight on bad news. He shows conservatism does not improve debt contracting efficiency. Gigler et al. (2009) extend the Venugopalan study to a more general setting and characterize the statistical nature of conservatism, showing the same result. Li (2009) incorporates the possibility of debt renegotiation. She shows conservatism may marginally increase the borrower's welfare when renegotiation is allowed, provided the renegotiation cost is neither too high nor too low.

We build on and extend these prior studies, but also differ from them in our modelling setup. For example, our firms do not control the disclosure of their cost reports. The cost reports are produced by an externally imposed accounting system, and the firms do not have discretion in the reporting process. Further, we assume the firms cannot communicate its true cost except through the accounting report. That is, the firm may know the accounting report carries a bias, but is not able to report the "true" cost through other channels. The firms' only strategic decision is on production quantity. Also, the banks in our model are strategic in their liquidation decisions. Upon receiving a bad cost report, the banks take 
over the decision rights of the firm. Conditional on the reports received, the banks may choose to liquidate a firm, continue a firm, or even choose to randomly liquidate a firm. This setup differs from Brander and Lewis (1986), in which firms are never liquidated before production. It also differs from Venugopalan (2004), Gigler et al. (2009), in which firms are always liquidated when bad signals are given. Further, we do not allow the firms and banks to renegotiate, as in $\mathrm{Li}$ (2009) . The banks in our model may choose to not liquidate a firm with bad cost reports, but the firms always choose to continue despite the true production cost.

The rest of the paper is organized as follows: Section 2 sets up the model. Section 3 presents the analyses and results. Section 4 concludes the paper.

\section{The Setup}

We examine the interaction between two firms $i$ and $j$ and their creditor(s). The two firms compete in Cournot fashion. As the focus of this paper is not the firms' optimal financial structure, we assume their operations are fully debt-financed. For each firm, the bank loans an amount of initial cash of $I$, and the face value of the loan for each firm is $D$.

The linear inverse demand function for the firms is $P=a-Q_{i}-Q_{j}$, where $P$ is the unit price for the product, $Q_{i}$ and $Q_{j}$ is the quantity produced and sold by each firm $i$ or $j$, $a$ is the intercept of market demand, with $a>0$. The firm $i$ 's marginal $\operatorname{cost} C_{i}$ is its private information. We assume $C_{i} \in\left\{c_{g}, c_{b}\right\}$, with $c_{b}>c_{g}>0$. The probability of the firm having a low marginal cost $C_{i}=c_{g}$ is $\theta$, while the probability of the firm having a high marginal $\operatorname{cost} C_{i}=c_{b}$ is $1-\theta$. The marginal costs of firm 1 and 2 are independent. Each firm's profit is $\Pi_{i}=Q_{i}\left(P-C_{i}\right)$.

Upon privately observing its own cost, each firm simultaneously discloses a signal of

cost $\widehat{C}_{i} \in\left\{\widehat{c}_{g}, \widehat{c}_{b}\right\}$ to the public. The report is observed by everyone, including the bank and the competitor. The signal may be biased by containing a certain degree of accounting distortion. When both firms simultaneously decide the quantities of their outputs, firm $i$ 
maximizes its profit conditional on the realized value of its own $\operatorname{cost} C_{i}$, its cost report, and its competitor's cost report. That is, the profit function for firm $i$ is

$$
\Pi_{i}=\Pi_{i}\left(C_{i}, \widehat{C}_{i}, \widehat{C}_{j}\right)=E\left(Q_{i}\left(a-Q_{i}-E\left(Q_{j}\right)-C_{i}\right)\right)
$$

The bank(s) and the firms use the cost signals for their debt covenants. If firm's reported cost signal is good, the firm's manager retians the decision rights of the firm. If the signal is bad, the bank takes over control rights and can liquidate the firm if needed. The reported cost signal is subject to the external accounting system. We model the firm's accounting system through two variables $\delta$ and $\gamma$ that represent the firms' reporting requirements, with $\delta \in[0,1]$ and $\gamma \in[0,1]$. Nature takes the first move, and decides whether firm $i$ 's cost is $c_{g}$ or $c_{b}$. A report is then produced by an exogenously determined accounting system. There are three different accounting systems: unbiased, conservative and aggressive. An unbiased accounting system is defined as generating a cost report consistent with the true cost with probability 1. A conservative accounting system is defined as generating a downward bias. Specifically, it generates a bad cost report with probability 1 when the true cost is bad; but generates a good cost report with probability $\gamma$ (and a bad cost report with probability $1-\gamma)$ when the true cost is good. An agressive accounting system is the opposite of the conservative accounting system, generating a good cost report with probability 1 when the true cost is good, and a bad cost report with probability $\delta$ (and a bad cost report with probability $1-\delta$ ) when the true cost is bad. We denote the posterior probabilities of true cost being consistent with the report as $\operatorname{Pr}\left[c_{g} \mid \hat{c}_{g}\right]=\alpha$ and $\operatorname{Pr}\left[c_{b} \mid \hat{c}_{b}\right]=\beta .^{5}$

\footnotetext{
${ }^{5}$ Essentially, the setup is similar in spirit to that of Venugopalan (2001). While his definition of accounting bias can go both directions, we restrict the bias in our systems to be distinctively one way.
} 


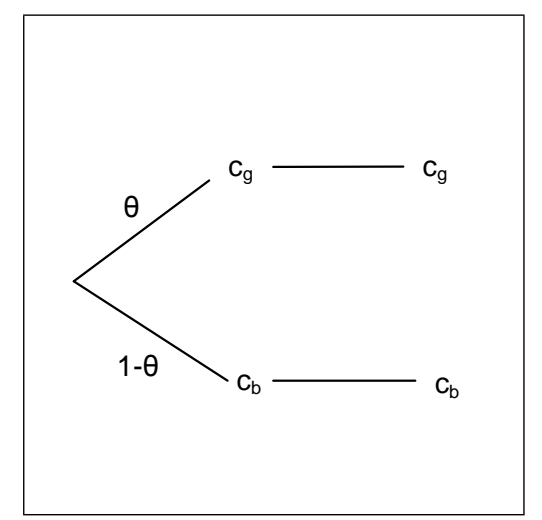

A. Unbiased system

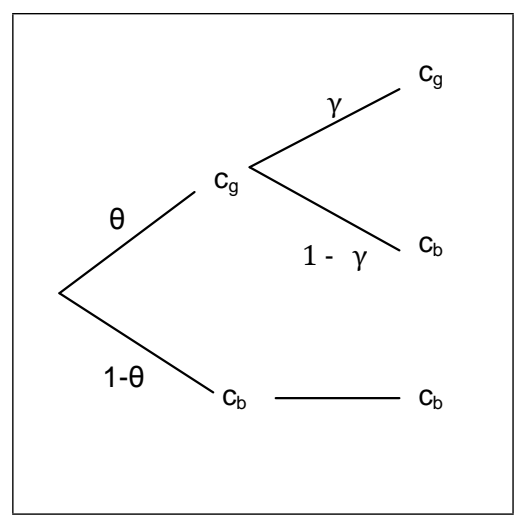

B. Conservative system

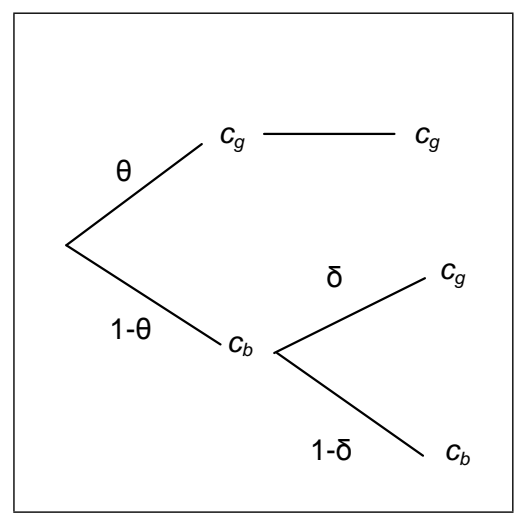

C. Agressive system

Figure 1. Illustration of different accounting systems

The accounting systems in our model can only bias accounting reports in one direction. That is, the conservative system only generates downwardly biased report and the aggressive system only generates upwardly biased report. The degree of bias is captured in the variables $\gamma$ and $\delta$. Specifically, the lower $\gamma$ the more conservative the conservative system is, and the higher $\delta$ the more agressive the agressive system is. Note that the case of agressive accounting systemis not a prevalent phenomenon in practice. We nevertheless examine it for the sake of completeness. The posterior probabilities under the three accounting systems are defined as:

$\begin{array}{lll}\text { Unbiased System: } & \alpha=1 & \beta=1 \\ \text { Conservative System: } & \alpha=1 & \beta=\frac{1-\theta}{(1-\theta)+\theta(1-\gamma)} \\ \text { Aggressive System: } & \alpha=\frac{\theta}{\theta+((1-\theta) \delta)} & \beta=1\end{array}$

The sequence of the game is as follows. At time 0, the firms borrow the needed cash from the bank(s). At time 1, nature reveals the firms' marginal costs, which can only be observed by the firms themselves. Each firm discloses a public signal that is generated by the firm's accounting system. The signal is observed by both the bank and the competitor. The firm's decision rights are controlled by the firm if the reported signal is good, and by the bank if the reported signal is bad. At time 2, the bank makes its decision to either continue or terminate the firm's operations. Thus at time 3 , there are three possible outcomes. If 
both firms are terminated, then there is no market. If only one firm survive, it becomes a monopoly. If both firms survives, there is Cournot competition. At time 4, the firms make respective quantity decisions. At last, payoffs are then realized for all parties involved at the end.

In the next sections, we analyze the role of the accounting system in several variations of the model described above. To establish a baseline, we first examine the impact of the accounting systems on firms' payoffs in a debt-free environment. Then we examine the accounting effect when two firms each borrow debt from two independent banks. The third case we investigate is when the two competing firms borrow from the same bank. In each of these cases, we contrast the results from an unbiased accounting system with that from a conservative system and an aggressive accounting system.

\section{Equity Financing}

We first examine the case when firms are fully equity-financed. Since there is no debt, there is no need for the bank. As described above, the two firms have the same binary cost realization. They then provide cost reports to the public. Finally the two firms compete based on the information they have.

\section{A. Unbiased Accounting System}

Suppose the firms' true costs have to be reported without any bias. That is, a good cost is reported as good with 100 percent probability, and a bad cost is reported as bad with 100 percent probability. It is in effect equivalent to firms' true costs being public knowledge. Since there is no imperfect information, we simply denote the firm profit as a function of its

own cost and the competitor's cost. For example, $\Pi\left(c_{g}, c_{g}\right)$ refers to firm profit when its own cost and its competitor's cost are both good. There are four possible levels of profit for firm $i$ :

1. With probability $\theta^{2}$, both firms have good cost realizations, and the firm profit from 
Cournot competition is $\Pi\left(c_{g}, c_{g}\right)=\frac{\left(a-c_{g}\right)^{2}}{9}$.

2. With probability $(1-\theta)^{2}$, both firms have bad cost realizations, and the firm profit from Cournot competition is $\Pi\left(c_{b}, c_{b}\right)=\frac{\left(a-c_{b}\right)^{2}}{9}$.

3. With probability $\theta(1-\theta)$, firm $i$ 's own cost is good and the competitor's cost is bad, and firm profit is $\Pi\left(c_{g}, c_{b}\right)=\frac{\left(\left(a-c_{g}\right)+\left(c_{b}-c_{g}\right)\right)^{2}}{9}$.

4. With probability $\theta(1-\theta)$, firm $i$ 's own cost is bad and the competitor's cost is good, and firm profit is $\Pi\left(c_{b}, c_{g}\right)=\frac{\left(\left(a-c_{b}\right)-\left(c_{b}-c_{g}\right)\right)^{2}}{9}$.

The total expected profit $E\left(\Pi_{u n b}\right.$. for firm $i$ is simply the weighted average of the above values. $^{6}$

\section{B. Conservative Accounting System}

Now we examine the case when the two competing firms are subject to an accounting system with conservative bias. Under conservative accounting system, the firms must report bad cost when the true cost is bad. But when the true cost is good, the firm may report good cost with probability $\gamma$ and report good cost with probability $1-\gamma$. A firm's profit is a function of its own cost, its reported cost and its competitor's reported cost. We denote a firm's profit and production quantity accordingly. For example, $\Pi\left(c_{g}, \widehat{c}_{g}, \widehat{c}_{g}\right)$ refers to the firm profit when its cost is good, its reported signal is good, and its competitor's reported cost is good.

With conservatively-biased accounting signal, there are 6 possible levels of firm profit:

1. With probability $\theta^{2} \gamma^{2}$, firm $i$ has good cost, reports good cost and its competitor also reports good cost. The firm's profit is $\Pi\left(c_{g}, \widehat{c}_{g}, \widehat{c}_{g}\right)=\frac{\left(a-c_{g}\right)^{2}}{9}$. This profit is the same as that under the unbiased accounting system when both firms have good costs. This is

\footnotetext{
${ }^{6}$ Note the total expected production quantities when there is perfect information and when there is symmetric imperfect information (when firms do not even know their own cost realization) are the same, but the total expected firm profits is higher when there is perfect information.
} 
because good signal is fully informative under conservative accounting system. Thus when both firms send out good cost signals, they both know their competitors' costs are truly good.

2. With probability $\theta^{2} \gamma(1-\gamma)$, firm $i$ has good cost, reports bad cost and its competitor reports good cost. The firm's profit is then $\Pi\left(c_{g}, \widehat{c}_{b}, \widehat{c}_{g}\right)=\frac{\left(2\left(a-c_{g}\right)-\beta\left(c_{b}-c_{g}\right)\right)^{2}}{36}$, with $\beta=$ $\frac{1-\theta}{(1-\theta)+\theta(1-\gamma)}$.

3. With probability $\theta \gamma(1-\theta)$, firm $i$ has bad cost, reports bad cost and its competitor reports good cost. The firm's profit is then $\Pi\left(c_{b}, \widehat{c}_{b}, \widehat{c}_{g}\right)=\frac{\left(2\left(a-c_{b}\right)-(1+\beta)\left(c_{b}-c_{g}\right)\right)^{2}}{36}$.

4. With probability $\theta \gamma(1-\theta \gamma)$, firm $i$ has good cost, reports good cost and its competitor reports bad cost. The firm's profit is then $\Pi\left(c_{g}, \widehat{c}_{g}, \widehat{c}_{b}\right)=\frac{\left(2\left(a-c_{g}\right)+2 \beta\left(c_{b}-c_{g}\right)\right)^{2}}{36}$.

5. With probability $\theta(1-\gamma)(1-\theta \gamma)$, firm $i$ has good cost, reports bad cost and its competitor reports bad cost. The firm's profit is then $\Pi\left(c_{g}, \widehat{c}_{b}, \widehat{c}_{b}\right)=\frac{\left(2\left(a-c_{g}\right)+\beta\left(c_{b}-c_{g}\right)\right)^{2}}{36}$.

6. With probability $(1-\theta)(1-\theta \gamma)$, firm $i$ has bad cost, reports bad cost and its competitor reports bad cost. The firm's profit is then $\Pi\left(c_{b}, \widehat{c}_{b}, \widehat{c}_{b}\right)=\frac{\left(2\left(a-c_{b}\right)-(1-\beta)\left(c_{b}-c_{g}\right)\right)^{2}}{36}$.

The expected firm profit $E\left(\Pi_{c o n}\right.$.) is the weighted-average of above firm profits.

\section{Agressive Accounting System}

Under an aggressive accounting system, the firms must report good cost when the true cost is good. But when the true cost is bad, the firm may report bad cost with probability $\delta$ and report good cost with probability $1-\delta$. There are also 6 possible levels of firm profit:

1. With probability $\theta(\theta+\delta-\theta \delta)$, firm $i$ has good cost, reports good cost and its competitor also reports good cost. The firm's profit is $\Pi\left(c_{g}, \widehat{c}_{g}, \widehat{c}_{g}\right)=\frac{\left(2\left(a-c_{g}\right)+(1-\alpha)\left(c_{b}-c_{g}\right)\right)^{2}}{36 b}$, with $\alpha=\frac{\theta}{\theta+((1-\theta) \delta)}$. 
2. With probability $\theta(1-\theta)(1-\delta)$, firm $i$ has good cost, reports good cost and its competitor reports bad cost. The firm's profit is then $\Pi\left(c_{g}, \widehat{c}_{g}, \widehat{c}_{b}\right)=\frac{\left(2\left(a-c_{g}\right)+(1+\alpha)\left(c_{b}-c_{g}\right)\right)^{2}}{36 b}$.

3. With probability $\delta(1-\theta)(\theta+\delta-\theta \delta)$, firm $i$ has bad cost, reports good cost and its competitor reports good cost. The firm's profit is then $\Pi\left(c_{b}, \widehat{c}_{g}, \widehat{c}_{g}\right)=\frac{\left(2\left(a-c_{b}\right)-\alpha\left(c_{b}-c_{g}\right)\right)^{2}}{36 b}$.

4. With probability $(1-\theta)^{2} \delta(1-\delta)$, firm $i$ has bad cost, reports good cost and its competitor reports bad cost. The firm's profit is then $\Pi\left(c_{b}, \widehat{c}_{g}, \widehat{c}_{b}\right)=\frac{\left(2\left(a-c_{b}\right)+\alpha\left(c_{b}-c_{g}\right)\right)^{2}}{36 b}$.

5. With probability $(1-\theta)(1-\delta)(\theta+\delta-\theta \delta)$, firm $i$ has bad cost, reports bad cost and its competitor reports good cost. The firm's profit is then $\Pi\left(c_{b}, \widehat{c}_{b}, \widehat{c}_{g}\right)=\frac{\left(2\left(a-c_{b}\right)-2 \alpha\left(c_{b}-c_{g}\right)\right)^{2}}{36 b}$.

6. With probability $(1-\theta)^{2}(1-\delta)^{2}$, firm $i$ has bad cost, reports bad cost and its competitor reports bad cost. The firm's profit is then $\Pi\left(c_{b}, \widehat{c}_{b}, \widehat{c}_{b}\right)=\frac{\left(a-c_{b}\right)^{2}}{9 b}$. This profit is the same as that under the unbiased accounting system when both firms have bad costs. This is because bad signal is fully informative under aggressive accounting system. Thus when both firms send out bad cost signals, they both know their competitors' costs are truly bad.

Again, the total expected firm profit $E\left(\Pi_{\text {agg. }}\right)$ is just the weighted average of the values outlined above.

By examining the firms' payoffs, it is obvious that the firms would always prefer to report good signal even when its true cost is bad. Thus under aggressive accounting system, the competing firms prefer to report aggressively.

Proposition 1. When firms compete in Cournot fashion in a debt-free world, their profits under conservative/aggressive accounting systems are strictly lower than that under unbiased accounting system, and their profits decreases with the level of conservatism/aggressiveness. Proof. See appendix.

Proposition 1 demonstrates that accounting bias decreases the amount of firm profit in a Cournot setting. The firms thus prefer a less biased accounting regime. The reason 
for the decreased profit is the efficiency loss caused by accounting distortion. Note there are two scenarios when the firm profit is higher under conservative accounting system than that under an unbiased accounting system: $\Pi\left(c_{g}, \widehat{c}_{g}, \widehat{c}_{b}\right)$ and $\Pi\left(c_{g}, \widehat{c}_{b}, \widehat{c}_{b}\right)$. However, the profits from the other four scenarios are all lower than that under unbiased accounting system. The losses thus outweigh the gains.

The following two figures visually demonstrate the efficiency loss due to accounting distortion.

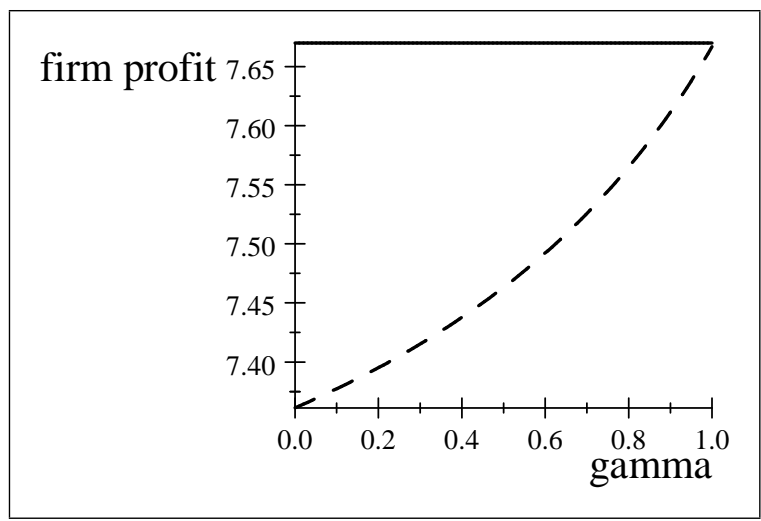

A: Conservative bias

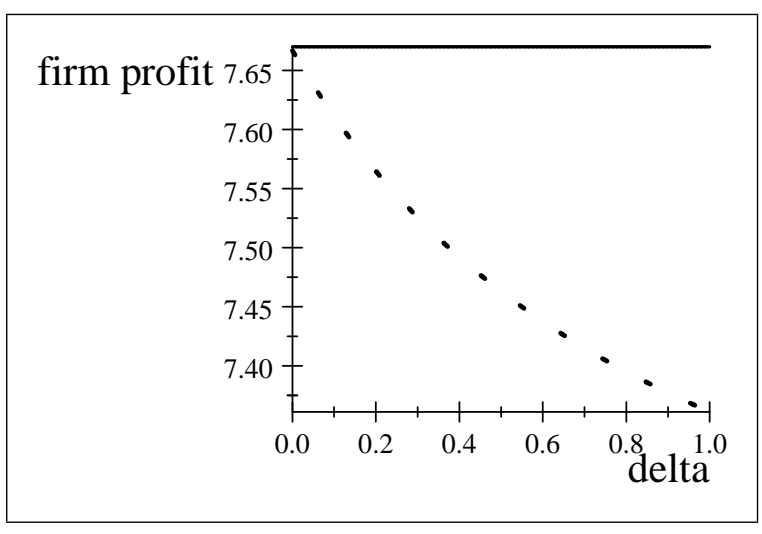

B: Aggressive bias

— unbiased system; - - - conservative system; $\cdots$ agressive system

Numerical values: $\theta=0.5, \mathrm{a}=10, \mathrm{c}_{g}=1, \mathrm{c}_{b}=3$.

Figure2: Firm profit level as a function of accounting bias.

\section{Debt Financing}

Now we introduce debt into the model. We assume the two competing firms each must finance their production through a different creditor. The probability distribution of cost is ex-ante known to all the players of the game. At time 0, each of the two firms borrows debt with face value $D$ from its creditor. The cash flow paid out to each firm by the creditor is I. The firms then disclose their costs generated by their reporting systems.

Absent renegotiation, it can be easily seen that the firm's owner will always prefer to 
continue the operations, since the payoff of termination is 0. However, the creditors will only prefer to continue when the payoff of continuing is higher than liquidation value $K$, which represents the depreciated firm assets at time 2. Note the creditors never have incentive to discontinue the operations if $K$ is sufficiently small. Thus here we assume $K$ is large enough to guarantee a more interesting story involving possible liquidation. When a good signal is reported, the firm's decision rights reside with the firm's owner who will continue the firm's operations. When a bad signal is reported, the firm's decision rights transfer to the creditor who may choose to liquidate. The payoffs for the banks and the borrowing firms are determined at the end of the timeline. When a firm reports a good signal, and hence does not violate the debt covenant, the bank gets $\min \{D ; \Pi\}$ and the firm gets $\max \{0, \Pi-D\}$. When a firm reports bad signal and is terminated by the bank, the bank gets the liquidation value $K$ and the firm gets 0 . When a firm reports bad signal but is allowed to continue by the bank, the bank gets $\Pi$ and the firm gets 0 .

\section{A. Unbiased Accounting System}

We first examine the firm payoffs under an unbiased accounting system. We assume the firms' liquidation value $K$ is higher than the profit level of a firm with bad cost that competes in the Cournot market. That is, $K>\Pi_{c}\left(c_{b}, c_{b}\right)>\Pi_{c}\left(c_{b}, c_{g}\right)$. (The subscript "c" denotes Cournot competition.) Thus the bank will always choose to discontinue the firm's operation whenever the firm's reported cost is bad.

An interesting consequence emerges when one firm reports good signal and the other bad signal. The firm with bad signal is liquidated, and the remaining firm becomes a monopolist, with a profit even higher than when both firms have good cost. That is, $\Pi_{m}\left(c_{g}\right)>\Pi_{c}\left(c_{g}, c_{g}\right)$. (Here the subscript " $m$ " denotes monopoly market.) The payoff table for the banks and firms 
is shown below:

\begin{tabular}{||c|l|l||}
\hline \hline $\begin{array}{c}\text { Bank 1;2 } \\
\text { Firm 1;2 }\end{array}$ & \multicolumn{1}{|c||}{ Prob. $=\theta$} & \multicolumn{1}{||}{ Prob. $=1-\theta$} \\
\hline Prob. $=\theta$ & $D ; D$ & $D ; K$ \\
& $\Pi_{c}\left(c_{g}, c_{g}\right)-D ; \Pi_{c}\left(c_{g}, c_{g}\right)-D$ & $\Pi_{m}\left(c_{g}\right)-D ; 0$ \\
\hline Prob. $=1-\theta$ & $K ; D$ & $K ; K$ \\
& $0 ; \Pi_{m}\left(c_{g}\right)-D$ & $0 ; 0$ \\
\hline
\end{tabular}

Table 1. Payoffs of banks/firms under unbiased accounting system

Each bank's expected payoff is

$$
\theta^{2} D+(1-\theta)^{2} K+\theta(1-\theta)(D+K)=K-K \theta+\theta D
$$

With the bank's zero profit constraint, we know $K-K \theta+\theta D=I$, and thus $D=\frac{I-K}{\theta}+K$. Firm $i$ 's expected payoff is

$$
\theta^{2}\left(\Pi_{c}\left(c_{g}, c_{g}\right)-D\right)+\theta(1-\theta)\left(\Pi_{m}\left(c_{g}\right)-D\right)
$$

where $\Pi_{c}\left(c_{g}, c_{g}\right)=\frac{\left(a-c_{g}\right)^{2}}{9}$ and $\Pi_{m}\left(c_{g}\right)=\frac{\left(a-c_{g}\right)^{2}}{4}$. Thus, firm $i$ 's expected profit is

$$
\begin{aligned}
E\left(\Pi_{\text {unb. }}\right) & =\theta^{2}\left(\frac{\left(a-c_{g}\right)^{2}}{9}-D\right)+\theta(1-\theta)\left(\frac{\left(a-c_{g}\right)^{2}}{4}-D\right) \\
& =\theta^{2} \frac{\left(a-c_{g}\right)^{2}}{9}+\theta(1-\theta) \frac{\left(a-c_{g}\right)^{2}}{4}-(I-K+\theta K)
\end{aligned}
$$

Bank's Decision. - The bank has three possible decision choices when receiving a bad cost report: to always continue, to always liquidate, or liquidate randomly. Obviously, if $K$ is lower than the firm's profit level, then the bank would always choose to let the firm with 
bad cost continue. In that case, the bank's payoff would then be

$$
\theta^{2} D+(1-\theta)^{2} \Pi_{c}\left(c_{b}, c_{b}\right)+\theta(1-\theta)\left(D+\Pi_{c}\left(c_{b}, c_{g}\right)\right)
$$

In the previous section, we assume the liquidation value $K$ is strictly higher than the firm profit level when its cost is bad. Thus the bank always liquidates a firm when the firm gives a bad report. However, a complication arises when the cost reports sent out by both firms are bad. If one bank chooses to let its borrowing firm continue, while the other bank liquidates the other borrowing firm, the remaining firm would turn into a monopolist and generates a profit $\Pi_{m}\left(c_{b}\right)$ that could be higher than $K$. When $\Pi_{m}\left(c_{b}\right)>K$, the banks could use a random strategy in liquidating the borrowing firms and improve the payoffs for all players.

Lemma 2. Under an unbiased accounting system, when both firms report bad cost, and when $\Pi_{m}\left(c_{b}\right)>K$, the banks may let their borrowing firms continue operating with probability $\frac{\Pi_{m}\left(c_{b}\right)-K}{\Pi_{m}\left(c_{b}\right)-\Pi_{c}\left(c_{b}, c_{b}\right)}$ to improve the total welfare of all players.

Proof. See Appendix.

Lemma 2 demonstrates the flexibility a competitive product market provides to the creditors of the firms competing in the market. Even when both firms are in bad condition, the random termination of one firm softens competition, thus give the remaining firm a chance to be profitable again. The optimal probability of liquidation is simply the usual ratio between the difference in payoffs induced by different decisions. Since the banks are assumed to earn zero profit, any gain from the random liquidation would be transferred to the borrowing firms in reduced interest rates. The random liquidation strategy thus provides a Pareto improvement to the payoffs of all players. ${ }^{7}$

Note that the effect demonstrated in Lemma 2 is independent of potential accounting

\footnotetext{
${ }^{7}$ We do not consider the potential welfare impact to consumers created by the change in product market structure. It is not immediately clear whether the consumer surplus would increase or decrease. For example, the random liquidation strategy could potentially improve consumer welfare since it prevents a complete market shutdown.
} 
influence, as there is no bias under unbiased accounting system. We show in the following section this effect could be amplified when the accounting system is biased. Also note the increase in number of firms in Cournot competition does not change the qualitative nature of the result. For simplicity, we include two competing firms in our model. As the number of firms competing in the same product market increases, the competition becomes more fierce. Nevertheless, the liquidation of one firm still softens the market competition and leaves the surviving firms better off.

\section{B. Conservative Accounting System}

Now we switch to the conservative accounting system. Following the same setup as under the unbiased accounting system, we first assume banks always liquidate the firms with a bad cost report. Thus, firms that have good cost but report bad cost under the conservative 
accounting system would also be liquidated.

\begin{tabular}{||l|l|l|l||}
\hline \hline Bank 1 & Prob. $=\theta \gamma$ & Prob. $=\theta(1-\gamma)$ & Prob. $=(1-\theta)$ \\
Bank 2 & & & \\
Firm 1 & & $K$ & $K$ \\
\hline \multirow{3}{*}{ Prob. $=\theta \gamma$} & $D$ & $D$ & $D$ \\
& $D$ & 0 & 0 \\
\hline Prob. $=\theta(1-\gamma)$ & $\Pi_{c}\left(c_{g}, c_{g}\right)-D$ & $\Pi_{m}\left(c_{g}\right)-D$ \\
\hline & $\Pi_{c}\left(c_{g}, c_{g}\right)-D$ & $\Pi_{m}\left(c_{g}\right)-D$ & $K$ \\
& $D$ & $K$ & $K$ \\
& 0 & $K$ & 0 \\
\hline Prob. $=(1-\theta)$ & $D$ & 0 & 0 \\
\hline \hline
\end{tabular}

Table 2. Payoffs of banks/firms under conservative accounting system.

Examining the payoff table, we can see the conservative accounting system induces inappropriate termination of firms with good cost. The total expected payoff to the bank is the weighted average of above values:

$$
\theta \gamma D+(1-\theta \gamma) K
$$

This payoff is lower than the bank payoff under the unbiased accounting system of 
$\theta D+(1-\theta) K$. With the bank facing the same zero profit constraint, we have

$$
D=\frac{I-K+\theta \gamma K}{\theta \gamma}
$$

Firm $i$ 's expected profit is

$$
E\left(\Pi_{\text {con. }}\right)=\theta^{2} \gamma^{2} \frac{\left(a-c_{g}\right)^{2}}{9}+\theta \gamma(1-\theta \gamma) \frac{\left(a-c_{g}\right)^{2}}{4}-(I-K+\theta \gamma K)
$$

Interestingly, under certain circumstances, the firms' expected profits under the conservative accounting system could even be higher than that under unbiased accounting system.

Proposition 3. When $(\theta+\theta \gamma)\left(\frac{\left(a-c_{g}\right)^{2}}{4}-\frac{\left(a-c_{g}\right)^{2}}{9}\right)>\left(\frac{\left(a-c_{g}\right)^{2}}{4}-K\right)$, and $\theta \neq 0, \gamma \neq 1$, the firms' expected profits are higher under the conservative accounting system than that under the unbiased accounting system.

Proof. See Appendix.

The above proposition demonstrates that accounting conservative bias induces two effects in the expected profits of the Cournot firms. One effect is the increased likelihood of a firm becoming a monopolist (as shown in Lemma 2). The second effect is the decreased chance of survival due to the creditors' excessive liquidation. When the first effect dominates the second, the firms' expected profits actually increase when there is an imposed conservative bias. Note that the second effect reduces the firm profit by the amount $\theta(1-\gamma)\left(\Pi_{m}\left(c_{g}\right)-K\right)$. This is because when a firm is liquidated, the creditor still gets liquidation value $K$. Since the creditors face zero-profit constraint, any extra value it gains will be still passed back to the firms through lower interest payments.

In addition, the firm's profit under the conservative accounting system depends on some parameter values.

Corollary 4. Under the conservative accounting system, the firms' profits decrease with the 
degree of accounting conservatism when $\Pi_{m}\left(c_{g}\right)-K>2 \theta \gamma\left(\Pi_{c}\left(c_{g}, c_{g}\right)-\Pi_{m}\left(c_{g}\right)\right)$; and increase with the degree of accounting conservatism when $\Pi_{m}\left(c_{g}\right)-K>2 \theta \gamma\left(\Pi_{d}\left(c_{g}, c_{g}\right)-\Pi_{m}\left(c_{g}\right)\right)$.

Proof. See Appendix.

The intuition behind the corollary 4 comes from the debts' role in changing the competitive nature of the industry. Although a conservative accounting system imposes excessive liquidation on firms that report a bad cost signal, it turns the surviving firm into a monopolist that generates higher profit than a Cournot duopolist. When the difference between the monopolist profit and duopolist profit is higher than the difference between the monopolist profit and the liquidation value, higher degree of conservatism actually increases firm profit.

Combining the findings of Proposition 3 and Corollary 4, we know that the firms' profits under the conservative accounting system could be higher than that under the unbiased accounting system when $\left(\Pi_{m}\left(c_{g}\right)-K\right)<(\theta+\theta \gamma)\left(\Pi_{m}\left(c_{g}\right)-\Pi_{c}\left(c_{g}, c_{g}\right)\right)$. Further, the firm profits increase as the degree of conservatism increases when $\Pi_{m}\left(c_{g}\right)-K<$ $2 \theta \gamma\left(\Pi_{m}\left(c_{g}\right)-\Pi_{c}\left(c_{g}, c_{g}\right)\right)$. This result is quite different from the prior literature on the effect of debt on conservatism, which typically shows conservatism decreases debt efficiency. The reason for the different result in our setting is due to the fact that accounting conservatism can indirectly change the industry structure through the firms' debt contracts.

Banks' Liquidation Decision. - Now we examine the creditors' decision to liquidate versus to let continue a firm that reports a bad signal. As under the unbiased accounting system, the liquidation decision largely depends on the value of $K$. If the banks never liquidate the firms with bad cost signals, the bank's payoff is

$$
\begin{aligned}
& \theta \gamma D+\theta^{2} \gamma(1-\gamma) \Pi_{c}\left(c_{g}, \widehat{c}_{b}, \widehat{c}_{g}\right)+\theta(1-\gamma)(1-\theta \gamma) \Pi_{c}\left(c_{g}, \widehat{c}_{b}, \widehat{c}_{b}\right) \\
& +\theta \gamma(1-\theta) \Pi_{c}\left(c_{b}, \widehat{c}_{b}, \widehat{c}_{g}\right)+(1-\theta)(1-\theta \gamma) \Pi_{c}\left(c_{b}, \widehat{c}_{b}, \widehat{c}_{b}\right) .
\end{aligned}
$$

Hence, the necessary condition for the bank to choose to always continue a firm with a 
bad cost signal is for the bank's payoff to be higher if this firm is continued. That is,

$$
\begin{aligned}
& \theta^{2} \gamma(1-\gamma) \Pi_{c}\left(c_{g}, \widehat{c}_{b}, \widehat{c}_{g}\right)+\theta(1-\gamma)(1-\theta \gamma) \Pi_{c}\left(c_{g}, \widehat{c}_{b}, \widehat{c}_{b}\right) \\
& +\theta \gamma(1-\theta) \Pi_{c}\left(c_{b}, \widehat{c}_{b}, \widehat{c}_{g}\right)+(1-\theta)(1-\theta \gamma) \Pi_{c}\left(c_{b}, \widehat{c}_{b}, \widehat{c}_{b}\right) \\
> & (1-\theta \gamma) K
\end{aligned}
$$

Obviously, the smaller the liquidation value $K$ is, the more likely it is the above inequality will hold. Conversely, when the bank knows the cost report issued by the firm it lends to is bad, and the cost report the rival firm sends out is good, the bank should always liquidate the firm if $(1-\beta) \Pi_{c}\left(c_{g}, \widehat{c}_{b}, \widehat{c}_{g}\right)+\beta \Pi_{c}\left(c_{b}, \widehat{c}_{b}, \widehat{c}_{g}\right)<K$.

Similar to Lemma 2, the bank could use a random strategy in the liquidation decision if $\Pi_{m}\left(c_{b}\right)>K$, when the cost reports sent out by both firms are bad.

Corollary 5. Under the conservative accounting system, when both firms report bad cost, and when $\Pi_{m}\left(c_{b}\right)>K$, the banks let their borrowing firms continue operating with probability $\frac{\beta \Pi_{m}\left(c_{b}\right)+(1-\beta) \Pi_{m}\left(c_{g}\right)-K}{\beta \Pi_{m}\left(c_{b}\right)+(1-\beta) \Pi_{m}\left(c_{g}\right)-\beta \Pi_{c}\left(c_{b}, \widehat{c}_{b}, \widehat{c}_{b}\right)+(1-\beta) \Pi_{c}\left(c_{g}, \widehat{c}_{b}, \widehat{c}_{b}\right)}$ to improve the total welfare of all players.

Proof. See Appendix.

The intuition of corollary 5 is similar to that of Lemma 2, except that the conservative bias in the accounting system effectively increases the decision space for the banks. The banks hence have more flexibility in their liquidation decisions to improve the players' payoffs.

\section{Aggressive accounting system}

Now we analyze when there is an aggressive accounting distortion in the firms' reports. Contrary to the conservative system, the firms must report good cost as good cost, and may report good or bad when the cost is truly bad. Again we first examine the payoff table of 
the banks and firms.

\begin{tabular}{|c|c|c|c|}
\hline $\begin{array}{l}\text { Bank } 1 \\
\text { Bank } 2 \\
\text { Firm } 1 \\
\text { Firm } 2\end{array}$ & Prob. $=\theta$ & $\begin{array}{l}\text { Prob. }= \\
(1-\theta) \delta\end{array}$ & $\begin{array}{l}\text { Prob. }= \\
(1-\theta)(1-\delta)\end{array}$ \\
\hline Prob. $=\theta$ & $\begin{array}{l}D \\
D \\
\Pi_{c}\left(c_{g}, \widehat{c}_{g}, c_{g}\right)-D \\
\Pi_{c}\left(c_{g} \widehat{c}_{g}, c_{g}\right)-D\end{array}$ & $\begin{array}{l}\Pi_{c}\left(c_{b}, \widehat{c}_{g}, c_{g}\right) \\
D \\
0 \\
\Pi_{c}\left(c_{g}, \widehat{c}_{g}, c_{b}\right)-D\end{array}$ & $\begin{array}{l}K \\
D \\
0 \\
\Pi_{m}\left(c_{g}\right)-D\end{array}$ \\
\hline $\begin{array}{l}\text { Prob. }= \\
(1-\theta) \delta\end{array}$ & $\begin{array}{l}D \\
\Pi_{c}\left(c_{b}, \widehat{c}_{g}, c_{g}\right) \\
\Pi_{c}\left(c_{g}, \widehat{c}_{g}, c_{b}\right)-D \\
0\end{array}$ & $\begin{array}{l}\Pi_{c}\left(c_{b}, \widehat{c}_{g}, c_{b}\right) \\
\Pi_{c}\left(c_{b}, \widehat{c}_{g}, c_{b}\right) \\
0 \\
0\end{array}$ & $\begin{array}{l}K \\
D \\
0 \\
\Pi_{m}\left(c_{b}\right)-D\end{array}$ \\
\hline $\begin{array}{l}\text { Prob. }= \\
(1-\theta)(1-\delta)\end{array}$ & $\begin{array}{l}D \\
K \\
\Pi_{m}\left(c_{g}\right)-D \\
0\end{array}$ & $\begin{array}{l}D \\
K \\
\Pi_{m}\left(c_{b}\right)-D \\
0\end{array}$ & $\begin{array}{l}K \\
K \\
0 \\
0\end{array}$ \\
\hline
\end{tabular}

Table 3. Payoffs of banks and firms under aggressive accounting system

Examining the payoff table, it is clear the problem under aggressive accounting system is the inappropriate continuation of firms with bad costs. The total expected payoff to the bank is:

$$
\begin{aligned}
& \left(\theta+(1-\theta)^{2} \delta(1-\delta)\right) D+\theta(1-\theta) \delta \Pi_{c}\left(c_{b} \widehat{c}_{g}, c_{g}\right) \\
& +(1-\theta)^{2} \delta^{2} \Pi_{c}\left(c_{b}, \widehat{c}_{g}, c_{b}\right)+(1-\theta)(1-\delta) K
\end{aligned}
$$


Again, the banks' payoffs are smaller compared to the banks' payoffs under the unbiased accounting system of $\theta D+(1-\theta) K$, since $\Pi_{c}\left(c_{b}, \widehat{c}_{g}, c_{g}\right)<K$ and $\Pi_{c}\left(c_{b}, \widehat{c}_{g}, c_{b}\right)<K$. With the bank facing the same zero profit constraint, we set the bank's payoff equal to $I$ and have

$$
D=\frac{\left(I-\theta(1-\theta) \delta \Pi_{c}\left(c_{b}, \widehat{c}_{g}, c_{g}\right)-(1-\theta)^{2} \delta^{2} \Pi_{c}\left(c_{b}, \widehat{c}_{g}, c_{b}\right)-(1-\theta)(1-\delta) K\right)}{\left(\theta+(1-\theta)^{2} \delta(1-\delta)\right)}
$$

then we have firm $i$ 's expected profit

$$
\begin{aligned}
E\left(\Pi_{\text {agg. }}\right)= & \theta^{2} \frac{\left(2\left(a-c_{g}\right)+\left(1-\frac{\theta}{\theta+((1-\theta) \delta)}\right)\left(c_{b}-c_{g}\right)\right)^{2}}{36} \\
& +\theta(1-\theta) \delta \frac{\left(2\left(a-c_{g}\right)+\left(1+\frac{\theta}{\theta+((1-\theta) \delta)}\right)\left(c_{b}-c_{g}\right)\right)^{2}}{36 b} \\
& +\theta(1-\theta)(1-\delta) \frac{\left(a-c_{g}\right)^{2}}{4}+(1-\theta) \delta(1-\delta) \frac{\left(a-c_{b}\right)^{2}}{4} \\
& -\left(\begin{array}{l}
-(1-\theta)^{2} \delta^{2} \frac{\left(2\left(a-c_{b}\right)+\frac{\theta}{\theta+((1-\theta) \delta)}\left(c_{b}-c_{g}\right)\right)^{2}}{36 b}-(1-\theta)(1-\delta) K
\end{array}\right)
\end{aligned}
$$

Compared to the firm's payoff under the unbiased accounting system, the firm's payoff is almost always lower, except that $\Pi_{c}\left(c_{g}, \widehat{c}_{g}, c_{g}\right)>\Pi_{c}\left(c_{g}, c_{g}\right)$ with probability $\theta^{2} .8$

Proposition 6. When $\theta^{2}\left(\Pi_{c}\left(c_{g} \widehat{c}_{g}, c_{g}\right)-\Pi_{c}\left(c_{g}, c_{g}\right)\right)>\left(\theta(1-\theta) \Pi_{m}\left(c_{g}\right)-(I-K+\theta K)\right)-$

$$
\left(\begin{array}{c}
\theta(1-\theta) \delta \Pi_{c}\left(c_{g} \widehat{c}_{g}, c_{b}\right)+\theta(1-\theta)(1-\delta) \Pi_{m}\left(c_{g}\right)+(1-\theta) \delta(1-\delta) \Pi_{m}\left(c_{b}\right) \\
-\left(I-\theta(1-\theta) \delta \Pi_{c}\left(c_{b} \widehat{c}_{g}, c_{g}\right)-(1-\theta)^{2} \delta^{2} \Pi_{c}\left(c_{b}, \widehat{c}_{g}, c_{b}\right)-(1-\theta)(1-\delta) K\right)
\end{array}\right), \text { and } \theta \neq
$$

$0, \delta \neq 1$, the firms' expected profits are higher under aggressive accounting system than that under unbiased accounting system.

Proof. The result is immediately clear from examining the expected firm profit levels under unbiased and aggressive accounting systems.

\footnotetext{
${ }^{8}$ The profit levels of firms with good costs competing under the agressive accounting system is higher than under unbiased accounting system. The reason is that under an agressive accounting system, the firms take into consideration that the rivals' reported good cost may not be true. The competition is thus softened as both firms lower their production quantities accordingly.
} 
The above proposition shows that only when $\theta$ is sufficiently large is it possible for an aggressive accounting system to induce higher profit for the firms than under unbiased system.

Banks' decision.-Without renegotiation, the banks have no way to prevent the problem of inappropriate continuation of firms with bad costs. The managers of the borrowing firms, on the other hand, have no incentive to terminate the firms by themselves. Thus there is no possible correction to the error induced by the aggressive accounting system.

\section{One Bank and Two Firms}

Now we introduce another scenario where the competing firms borrow from the same creditor. The change from two creditors to one common creditor is non-trivial. The firms' cost realizations are independent of each other, and the common creditor in our model still cannot infer one firm's cost from the other. However, now the single creditor is able to manipulate the competitive nature of the market by strategic liquidation. The payoffs with one creditor are mostly the same as when there are two banks lending to two firms, but the bank maximizes its payoff from the whole industry rather than from each individual firm. Therefore, when both firms report bad cost signals, the bank may be better off letting one firm survive. Especially, when the profit of a monopolist with bad cost $\Pi_{m}\left(c_{b}\right)>K$, the strategic liquidation provides a Pareto improvement on all players' payoffs.

\section{A. Unbiased accounting system}

We again first examine the payoffs under the unbiased accounting system. The payoff to the bank is essentially the sum of the two banks in the previous analyses. Examining the lower right cell of Table 1, in which both firms report bad cost signals, the best the two banks can do is to use random strategy to liquidate the firms (as described in Lemma 1). However, when there is one bank lending to both firms, it is able to deterministically let one 
firm liquidate and the other continue as a monopolist. Its payoff is thus:

$$
\theta^{2} 2 D+(1-\theta)^{2}\left(K+\Pi_{m}\left(c_{b}\right)\right)+2 \theta(1-\theta)(D+K)
$$

Since the above must equal the total initial cash investment $2 I$, we know

$$
D=\frac{2 I-(1-\theta)^{2} \Pi_{m}\left(c_{b}\right)-(1-\theta)(1+\theta) K}{2 \theta}
$$

which is strictly lower than $\frac{I-(1-\theta) K}{\theta}$ if the bank does not perform such random liquidation. Since the bank faces zero-profit constraint, all the extra profit is transferred to the firms through lower interest rate. Firm $i$ 's payoff is

$$
\begin{aligned}
& \theta^{2}\left(\Pi_{d}\left(c_{g}, c_{g}\right)-D\right)+\theta(1-\theta)\left(\Pi_{m}\left(c_{g}\right)-D\right) \\
= & \theta^{2} \Pi_{d}\left(c_{g}, c_{g}\right)+\theta(1-\theta) \Pi_{m}\left(c_{g}\right)-\frac{2 I-(1-\theta)^{2} \Pi_{m}\left(c_{b}\right)-(1-\theta)(1+\theta) K}{2}
\end{aligned}
$$

which is strictly higher than $\theta^{2} \Pi_{d}\left(c_{g}, c_{g}\right)+\theta(1-\theta) \Pi_{m}\left(c_{g}\right)-(I-K+K \theta)$, the payoff should such random liquidation not occur.

\section{B. Conservative accounting system}

Compared to the unbiased accounting system, the probability of both firms reporting a bad cost is higher under the conservative accounting system. In fact, the four lower right cells in Table 2 all contain double liquidations. With one bank lending to both firms, one liquidation and one monopolist survivor would replace these cells instead. The bank's expected payoff would then be:

$$
2 \theta \gamma D+2 \theta \gamma(1-\theta \gamma) K+\theta(1-\gamma)(1-\theta \gamma) \Pi_{m}\left(c_{g}\right)+(1-\theta)(1-\theta \gamma) \Pi_{m}\left(c_{b}\right)
$$

This payoff is greater than the bank payoff under strategic random liquidation. Again 
we compute the face value of the debt:

$$
D=\frac{2 I-2 \theta \gamma(1-\theta \gamma) K-\theta(1-\gamma)(1-\theta \gamma) \Pi_{m}\left(c_{g}\right)-(1-\theta)(1-\theta \gamma) \Pi_{m}\left(c_{b}\right)}{2 \theta \gamma}
$$

which is smaller than if the bank does not perform the random liquidation.

The firm $i$ 's expected profit is thus

$$
\begin{aligned}
& \theta^{2} \gamma^{2} \Pi_{c}\left(c_{g}, c_{g}\right)+\theta \gamma(1-\theta \gamma) \Pi_{m}\left(c_{g}\right)- \\
& \frac{2 I-2 \theta \gamma(1-\theta \gamma) K-\theta(1-\gamma)(1-\theta \gamma) \Pi_{m}\left(c_{g}\right)-(1-\theta)(1-\theta \gamma) \Pi_{m}\left(c_{b}\right)}{2}
\end{aligned}
$$

\section{Aggressive Accounting System}

As shown in Table 3, the aggressive accounting system also has one cell where both firms are liquidated. The single bank that lends to both firms could also replicate the same strategy to liquidate one firm and turn the surviving rival into a monopolist. However, the probability of both firms report bad cost is much smaller than that under conservative system.

The results of above finding is summarized in the following proposition.

Proposition 7. Under all accounting systems, when two competing firms borrow from one common bank, the bank may improve the overall payoffs by turning one of the two firms that report a bad cost into a surviving monopolist.

Proof. The result is immediately clear from examining the banks/firms payoffs.

\section{Conclusion}

We show accounting biases decrease the expected firm profits when the firms compete in Cournot product market in a debt-free world. However, some different results emerge when debt is introduced into the firms' financial structure. Specifically, when accounting reports are used for debt covenants, accounting biases affect the likelihood of covenant violation 
and the banks' subsequent liquidation decision. When one of the two firms is terminated, the other one becomes a monopolist. The surviving firm is then able to capture the entire market share,making a profit higher than when it competes with a rival firm. We then demonstrate the firms' payoffs under the conservative accounting system could be higher than that under the unbiased accounting system. In addition, the conservative accounting system provides the creditors with more control by triggering debt covenant violation more frequently. The creditors can reduce "false positives" by not always terminating firms with bad reports. Further, the creditors can choose to randomly allow one firm to survive when both firms report bad signals. The remaining monopolist then generates enough profit to pay back the debt. With assumption of zero-profit constraint for the bank, the extra gain from conservative accounting is passed to the firms through decreased interest rates.

Our study shows accounting bias could have a real effect on the firms' operating decisions through the presence of debt. Accounting is often perceived to be just a distortion of information, and not have real impact on the economic agents' behavior. However, the accounting bias in our setting could change the competitive nature of market in which the borrowing firms compete.

\section{REFERENCES}

Athey, S., and K. Bagwell. 2001. Optimal collusion with private information. RAND Journal of Economics, 32 (3), 428-465.

Bagwell, K., 1995. Commitment and observability in games. Games and Economic Behavior, $8(2), 271-280$.

Bagnoli, M., and S.G. Watts, 2010. Oligopoly, disclosure, and earnings management. The Accounting Review, 85 (June).

Basu, S., 1997. The conservatism principle and the asymmetric timeliness of earnings. Journal of Accounting and Economics, 24, 3-37. 
Beatty, A., J. Webber and J. Yu, 2008. Conservatism and debt. Journal of Accounting and Economics, 45 (2-3), 157-174.

Brander, J.A., and T.R. Lewis, 1986. Oligopoly and financial structure: The limited liability effect. The American Economic Review, 76 (5), 956-970.

Corona, C., and Nan, L., 2010. Bluffing contests: The real effects of pre-announcing competitive decisions. Working paper, Carnegie-Mellon University

Clayton, M. J. and B. Jorgensen 2005, Optimal Cross Holding with Externalities and Strategic Interactions. Journal of Business, Vol. 78, No. 4, July, pp. $1505-1522$.

Demerjian, P., 2011. Accounting Standards and Debt Covenants: Has the "Balance Sheet Approach" Led to a Decline in the Use of Balance Sheet Covenants?" Journal of Accounting and Economics, forthcoming.

Darrough, M., 1993. Disclosure bolicy and competition: Cournot vs. Bertrand. The Accounting Review, 68 (3), 534-561.

Darrough, M. N. and N M. Stoughton. Financial Disclosure Policy in an Entry Game. Journal of Accounting and Economics 12 (1990), 219-243

Gigler, F., C. Kanodia, H. Sapra and R. Venugopalan, 2009. Accounting conservatism and the effciency of debt contracts. Journal of Accounting Research 47 (3), 767-797.

Hughes, J.S., J. Kao, and A. Mukherji, 1998. Oligopoly, financial structure, and resolution of uncertainty. Journal of economics and Management Strategy, 7 (1), 67-88.

Hughes, J.S., and M.G. Williams, 2008. Commitment and disclosure in oligopolies. The Accounting Review, 83 (1).

Li, J. 2009. Accounting Conservatism and Debt Contracts: Efficient Liquidation and Covenant Renegotiation. Working paper, Carnegie-Mellon University 
Venugopalan, R., 2004. Conservatism in accounting: good or bad? Working paper, University of Chicago.

Watts, R.L., 2003. Conservatism in accounting Part I: Explanations and implications. Accounting Horizons, 3, 207-221.

\section{Appendix}

\section{A Computation of the firm profits in the debt-free world}

To compute the expected firm profit, we must compute the firm profits for each of the six scenarios under both conservative and aggressive systems.

\section{A. With Conservative Bias}

Scenario 1: When both firms report good signals. - When firm $i$ has good cost, reports good cost and its competitor firm $j$ also reports good cost, we know both firms must be reporting truthfully, since $\alpha=1$. That is, both firms must have the same true cost and same reported cost. Thus the problem reduces to a standard Cournot game. Firm $i$ ' objective function is:

$$
q_{i}\left(c_{g}, \widehat{c}_{g}, \widehat{c}_{g}\right)\left(a-q_{i}\left(c_{g}, \widehat{c}_{g}, \widehat{c}_{g}\right)-q_{j}\left(c_{g}, \widehat{c}_{g}, \widehat{c}_{g}\right)-c_{g}\right)
$$

Firm $j$ ' objective function is:

$$
q_{j}\left(c_{g}, \widehat{c}_{g}, \widehat{c}_{g}\right)\left(a-q_{j}\left(c_{g}, \widehat{c}_{g}, \widehat{c}_{g}\right)-q_{i}\left(c_{g}, \widehat{c}_{g}, \widehat{c}_{g}\right)-c_{g}\right)
$$

Both firms maximize their profit functions over $q$. Setting the two FOCs equal to zero and solve for $q_{i}$ and $q_{j}$, we have:

$$
q_{i}\left(c_{g}, \widehat{c}_{g}, \widehat{c}_{g}\right)=q_{j}\left(c_{g}, \widehat{c}_{g}, \widehat{c}_{g}\right)=\frac{a-c_{g}}{3}
$$


Substitute into the profit function, we have:

$$
\Pi_{c}\left(c_{g}, \widehat{c}_{g}, \widehat{c}_{g}\right)=\frac{\left(a-c_{g}\right)^{2}}{9}
$$

Scenarios 2, 3 and 4: When one firm reports good signal and one firm reports bad signal. - Suppose firm $i$ reports a good signal and firm $j$ reports a bad signal. Firm $i$ must have true good cost. Firm $j$ could have true bad cost or have good cost but report a bad cost. The three FOCs are:

$$
q_{i}\left(c_{g}, \widehat{c}_{g}, \widehat{c}_{b}\right)=\frac{a-c_{g}-\left(\beta q_{j}\left(c_{b}, \widehat{c}_{b}, \widehat{c}_{g}\right)+(1-\beta) q_{j}\left(c_{g}, \widehat{c}_{b}, \widehat{c}_{g}\right)\right)}{2}
$$

Solving for the three unknowns and applying symmetry, we have:

$$
\begin{gathered}
q\left(c_{g}, \widehat{c}_{g}, \widehat{c}_{b}\right)=\frac{2\left(a-c_{g}\right)+2 \beta\left(c_{b}-c_{g}\right)}{6} \\
q\left(c_{g}, \widehat{c}_{b}, \widehat{c}_{g}\right)=\frac{2\left(a-c_{g}\right)-\beta\left(c_{b}-c_{g}\right)}{6} \\
q\left(c_{b}, \widehat{c}_{b}, \widehat{c}_{g}\right)=\frac{2\left(a-c_{b}\right)-(1+\beta)\left(c_{b}-c_{g}\right)}{6}
\end{gathered}
$$


The corresponding firm profits are:

$$
\begin{gathered}
\Pi\left(c_{g}, \widehat{c}_{g}, \widehat{c}_{b}\right)=\frac{\left(2\left(a-c_{g}\right)+2 \beta\left(c_{b}-c_{g}\right)\right)^{2}}{36} \\
\Pi\left(c_{g}, \widehat{c}_{b}, \widehat{c}_{g}\right)=\frac{\left(2\left(a-c_{g}\right)-\beta\left(c_{b}-c_{g}\right)\right)^{2}}{36} \\
\Pi\left(c_{b}, \widehat{c}_{b}, \widehat{c}_{g}\right)=\frac{\left(2\left(a-c_{b}\right)-(1+\beta)\left(c_{b}-c_{g}\right)\right)^{2}}{36}
\end{gathered}
$$

Scenarios 5 and 6: When both firms report bad signals. - When two bad signals are reported, the competing firms have symmetric imperfect information. Each firm must take into consideration that the competitor could have truly bad cost, or have good cost but report bad. Firm $i$ maximizes its profit by choosing production quantity $q_{i}$ so that $\frac{\partial}{\partial q_{i}}\left(q_{i}\left(a-q_{i}-E\left(q_{j}\right)-c_{i}\right)=0\right.$, where $E\left(q_{j}\right)=\beta q_{j}\left(c_{b}, \widehat{c}_{b}, \widehat{c}_{b}\right)+(1-\beta) q_{j}\left(c_{g}, \widehat{c}_{b}, \widehat{c}_{b}\right)$. Firm $j$ does the same. Applying symmetry, we have the following four equations:

$$
q_{i}\left(c_{b}, \widehat{c}_{b}, \widehat{c}_{b}\right)=\frac{1}{2}\left(a-c_{b}-\beta q_{j}\left(c_{b}, \widehat{c}_{b}, \widehat{c}_{b}\right)-(1-\beta) q_{j}\left(c_{g}, \widehat{c}_{b}, \widehat{c}_{b}\right)\right)
$$

$$
q_{i}\left(c_{g}, \widehat{c}_{b}, \widehat{c}_{b}\right)=\frac{1}{2}\left(a-c_{g}-\beta q_{j}\left(c_{b}, \widehat{c}_{b}, \widehat{c}_{b}\right)-(1-\beta) q_{j}\left(c_{g}, \widehat{c}_{b}, \widehat{c}_{b}\right)\right)
$$

$$
q_{j}\left(c_{b}, \widehat{c}_{b}, \widehat{c}_{b}\right)=\frac{1}{2}\left(a-c_{b}-\beta q_{i}\left(c_{b}, \widehat{c}_{b}, \widehat{c}_{b}\right)-(1-\beta) q_{i}\left(c_{g}, \widehat{c}_{b}, \widehat{c}_{b}\right)\right)
$$

$$
q_{j}\left(c_{g}, \widehat{c}_{b}, \widehat{c}_{b}\right)=\frac{1}{2}\left(a-c_{g}-\beta q_{i}\left(c_{b}, \widehat{c}_{b}, \widehat{c}_{b}\right)-(1-\beta) q_{i}\left(c_{g}, \widehat{c}_{b}, \widehat{c}_{b}\right)\right)
$$


Solving the four equations and applying symmetry, we have:

$$
q\left(c_{g}, \widehat{c}_{b}, \widehat{c}_{b}\right)=\frac{2\left(a-c_{g}\right)+\beta\left(c_{b}-c_{g}\right)}{6}
$$

$$
q\left(c_{b}, \widehat{c}_{b}, \widehat{c}_{b}\right)=\frac{2\left(a-c_{b}\right)-(1-\beta)\left(c_{b}-c_{g}\right)}{6}
$$

Firm $i$ 's profit is:

$$
\begin{gathered}
\Pi\left(c_{g}, \widehat{c}_{b}, \widehat{c}_{b}\right)=\frac{\left(2\left(a-c_{g}\right)+\beta\left(c_{b}-c_{g}\right)\right)^{2}}{36} \\
\Pi\left(c_{b}, \widehat{c}_{b}, \widehat{c}_{b}\right)=\frac{\left(2\left(a-c_{b}\right)-(1-\beta)\left(c_{b}-c_{g}\right)\right)^{2}}{36}
\end{gathered}
$$

\section{B. With Aggressive Bias}

Scenarios 1 and 2: when both firms report good signals.-When two good signals are reported, the firms could have truly good cost, or have bad cost but report good. Thus, firm $i$ 's objective function is $q_{i}\left(a-q_{i}-E\left(q_{j}\right)-c_{i}\right.$, where $E\left(q_{j}\right)=\alpha q_{j}\left(c_{g}, \widehat{c}_{g}, \widehat{c}_{g}\right)+$ $(1-\alpha) q_{j}\left(c_{b}, \widehat{c}_{g}, \widehat{c}_{g}\right)$. Firm $j$ does the same. Applying symmetry, we have 4 equations:

$$
q_{i}\left(c_{g}, \widehat{c}_{g}, \widehat{c}_{g}\right)=\frac{1}{2}\left(a-c_{g}-\alpha q_{j}\left(c_{g}, \widehat{c}_{g} \widehat{c}_{g}\right)-(1-\alpha) q_{j}\left(c_{b}, \widehat{c}_{g}, \widehat{c}_{g}\right)\right)
$$

$$
\begin{aligned}
& q_{i}\left(c_{b}, \widehat{c}_{g}, \widehat{c}_{g}\right)=\frac{1}{2}\left(a-c_{b}-\alpha q_{j}\left(c_{g}, \widehat{c}_{g}, \widehat{c}_{g}\right)-(1-\alpha) q_{j}\left(c_{b}, \widehat{c}_{g}, \widehat{c}_{g}\right)\right) \\
& q_{j}\left(c_{g}, \widehat{c}_{g}, \widehat{c}_{g}\right)=\frac{1}{2}\left(a-c_{g}-\alpha q_{i}\left(c_{g}, \widehat{c}_{g}, \widehat{c}_{g}\right)-(1-\alpha) q_{i}\left(c_{b}, \widehat{c}_{g}, \widehat{c}_{g}\right)\right)
\end{aligned}
$$




$$
q_{j}\left(c_{b}, \widehat{c}_{g}, \widehat{c}_{g}\right)=\frac{1}{2}\left(a-c_{b}-\alpha q_{i}\left(c_{g}, \widehat{c}_{g}, \widehat{c}_{g}\right)-(1-\alpha) q_{i}\left(c_{b}, \widehat{c}_{g}, \widehat{c}_{g}\right)\right)
$$

Solving the four equations and applying symmetry, we have:

$$
q\left(c_{g}, \widehat{c}_{g}, \widehat{c}_{g}\right)=\frac{2\left(a-c_{g}\right)+(1-\alpha)\left(c_{b}-c_{g}\right)}{6}
$$

$$
q\left(c_{b}, \widehat{c}_{g}, \widehat{c}_{g}\right)=\frac{2\left(a-c_{b}\right)-\alpha\left(c_{b}-c_{g}\right)}{6}
$$

Firm $i$ 's profit is:

$$
\Pi\left(c_{g}, \widehat{c}_{g}, \widehat{c}_{g}\right)=\frac{\left(2\left(a-c_{g}\right)+(1-\alpha)\left(c_{b}-c_{g}\right)\right)^{2}}{36}
$$

$$
\Pi\left(c_{b}, \widehat{c}_{g}, \widehat{c}_{g}\right)=\frac{\left(2\left(a-c_{b}\right)-\alpha\left(c_{b}-c_{g}\right)\right)^{2}}{36}
$$

\section{Scenarios 3, 4 and 5: When one firm reports a good signal and one firm} reports a bad signal. - Let firm $i$ report a good signal and firm $j$ report a bad signal. Firm $i$ could have true good cost or have bad cost but report good cost. Firm $j$ must have true bad cost. The three FOCs are:

$$
\begin{gathered}
q_{i}\left(c_{g}, \widehat{c}_{g}, \widehat{c}_{b}\right)=\frac{a-c_{g}-q_{j}\left(c_{b}, \widehat{c}_{b}, \widehat{c}_{g}\right)}{2} \\
q_{i}\left(c_{b}, \widehat{c}_{g}, \widehat{c}_{b}\right)=\frac{a-c_{b}-q_{j}\left(c_{b}, \widehat{c}_{b}, \widehat{c}_{g}\right)}{2} \\
q_{j}\left(c_{b}, \widehat{c}_{b}, \widehat{c}_{g}\right)=\frac{a-c_{g}-\left(\alpha q_{i}\left(c_{g}, \widehat{c}_{g}, \widehat{c}_{b}\right)+(1-\alpha) q_{i}\left(c_{b}, \widehat{c}_{g}, \widehat{c}_{b}\right)\right)}{2}
\end{gathered}
$$


Solving for the three unknowns and applying symmetry, we have:

$$
q\left(c_{g}, \widehat{c}_{g}, \widehat{c}_{b}\right)=\frac{2\left(a-c_{g}\right)+(1+\alpha)\left(c_{b}-c_{g}\right)}{6}
$$

$$
q\left(c_{b}, \widehat{c}_{g}, \widehat{c}_{b}\right)=\frac{2\left(a-c_{b}\right)+\alpha\left(c_{b}-c_{g}\right)}{6}
$$

And the corresponding firm profits are:

$$
\begin{gathered}
\Pi\left(c_{g}, \widehat{c}_{g}, \widehat{c}_{b}\right)=\frac{\left(2\left(a-c_{g}\right)+(1+\alpha)\left(c_{b}-c_{g}\right)\right)^{2}}{36} \\
\Pi\left(c_{b} \widehat{c}_{g}, \widehat{c}_{b}\right)=\frac{\left(2\left(a-c_{b}\right)+\alpha\left(c_{b}-c_{g}\right)\right)^{2}}{36} \\
\Pi\left(c_{b}, \widehat{c}_{b}, \widehat{c}_{g}\right)=\frac{\left(2\left(a-c_{b}\right)-2 \alpha\left(c_{b}-c_{g}\right)\right)^{2}}{36}
\end{gathered}
$$

Scenario 6: When both firms report bad signals. - Under aggressive accounting system, the firms must have truly bad cost when they both report bad signals. Thus again the problem reduces to a standard Cournot game. Firm $i$ 's FOC is:

$$
q_{i}\left(c_{b}, \widehat{c}_{b}, \widehat{c}_{b}\right)=q_{j}\left(c_{b}, \widehat{c}_{b}, \widehat{c}_{b}\right)=\frac{a-c_{b}}{3} .
$$

Substituting into the profit function, we have:

$$
\Pi\left(c_{b}, \widehat{c}_{b}, \widehat{c}_{b}\right)=\frac{\left(a-c_{b}\right)^{2}}{9}
$$




\section{B Proof of Proposition 1}

The expected payoffs of firm $i$ in three different accounting systems are listed below.

Unbiased system:

(B1)

$$
\begin{aligned}
E\left(\Pi_{\text {unb. }}\right)= & \theta^{2} \frac{\left(a-c_{g}\right)^{2}}{9}+(1-\theta)^{2} \frac{\left(a-c_{b}\right)^{2}}{9} \\
& +\theta(1-\theta) \frac{\left(\left(a-c_{g}\right)+\left(c_{b}-c_{g}\right)\right)^{2}}{9}+(1-\theta) \theta \frac{\left(\left(a-c_{b}\right)-\left(c_{b}-c_{g}\right)\right)^{2}}{9}
\end{aligned}
$$

Conservative system:

$$
\begin{aligned}
E\left(\Pi_{\text {con. }}\right)= & \theta^{2} \gamma^{2} \frac{\left(a-c_{g}\right)^{2}}{9}+\theta \gamma \theta(1-\gamma) \frac{\left(2\left(a-c_{g}\right)-\frac{1-\theta}{(1-\theta)+\theta(1-\gamma)}\left(c_{b}-c_{g}\right)\right)^{2}}{36} \\
& +\theta \gamma(\theta(1-\gamma)+(1-\theta)) \frac{\left(2\left(a-c_{g}\right)+2 \frac{1-\theta}{(1-\theta)+\theta(1-\gamma)}\left(c_{b}-c_{g}\right)\right)^{2}}{36} \\
& +\theta(1-\gamma)(\theta(1-\gamma)+(1-\theta)) \frac{\left(2\left(a-c_{g}\right)+\frac{1-\theta}{(1-\theta)+\theta(1-\gamma)}\left(c_{b}-c_{g}\right)\right)^{2}}{36} \\
& +\theta \gamma(1-\theta) \frac{\left(2\left(a-c_{b}\right)-\left(1+\frac{1-\theta}{(1-\theta)+\theta(1-\gamma)}\right)\left(c_{b}-c_{g}\right)\right)^{2}}{36} \\
& +(1-\theta)(\theta(1-\gamma)+(1-\theta)) \frac{\left(2\left(a-c_{b}\right)-\left(1-\frac{1-\theta}{(1-\theta)+\theta(1-\gamma)}\right)\left(c_{b}-c_{g}\right)\right)^{2}}{36}
\end{aligned}
$$


Aggressive system:

$$
\begin{aligned}
E\left(\Pi_{\text {agg. }}\right)= & \left(\theta^{2}+\theta(1-\theta) \delta\right) \frac{\left(2\left(a-c_{g}\right)+\left(1-\frac{\theta}{\theta+((1-\theta) \delta)}\right)\left(c_{b}-c_{g}\right)\right)^{2}}{36} \\
& +\theta(1-\theta)(1-\delta) \frac{\left(2\left(a-c_{g}\right)+\left(1+\frac{\theta}{\theta+((1-\theta) \delta)}\right)\left(c_{b}-c_{g}\right)\right)^{2}}{36} \\
(\mathrm{~B} 3) \quad & +\left(\theta(1-\theta) \delta+(1-\theta)^{2} \delta^{2}\right) \frac{\left(2\left(a-c_{b}\right)-\frac{\theta}{\theta+((1-\theta) \delta)}\left(c_{b}-c_{g}\right)\right)^{2}}{36} \\
& +(1-\theta) \delta(1-\theta)(1-\delta) \frac{\left(2\left(a-c_{b}\right)+\frac{\theta}{\theta+((1-\theta) \delta)}\left(c_{b}-c_{g}\right)\right)^{2}}{36} \\
& +(\theta(1-\theta)(1-\delta)+(1-\theta) \delta(1-\theta)(1-\delta)) \frac{\left(2\left(a-c_{b}\right)-2 \frac{\theta}{\theta+((1-\theta) \delta)}\left(c_{b}-c_{g}\right)\right)^{2}}{36} \\
& +(1-\theta)^{2}(1-\delta)^{2} \frac{\left(a-c_{b}\right)^{2}}{9}
\end{aligned}
$$

To compute the difference in these profits, we subtract the conservative/aggressive profit from the unbiased profit.

$$
\begin{gathered}
E\left(\Pi_{\text {unb. }}\right)-E\left(\Pi_{\text {con. }}\right)=\frac{11}{36} \theta\left(c_{b}-c_{g}\right)^{2}(1-\theta) \frac{1-\gamma}{1-\theta \gamma}>0 \\
E\left(\Pi_{\text {unb. }}\right)-E\left(\Pi_{\text {agg. }}\right)=\frac{11}{36} \theta \delta\left(c_{b}-c_{g}\right)^{2} \frac{1-\theta}{\theta+\delta-\theta \delta}>0
\end{gathered}
$$

Thus we know the profit level under unbiased accounting system is always higher than that under conservative/aggressive accounting system.

To demonstrate the relationship between the firm profit and the level of conservative/aggressive bias, we take the partial derivative of firm $i$ 's profit w.r.t. $\gamma$ and $\delta$.

$$
\frac{\partial}{\partial \gamma} E\left(\Pi_{\text {con. }}\right)=\frac{11}{36} \theta\left(c_{b}-c_{g}\right)^{2} \frac{(\theta-1)^{2}}{(\theta \gamma-1)^{2}}>0
$$




$$
\frac{\partial}{\partial \gamma} E\left(\Pi_{\text {agg. }}\right)=\frac{11}{36} \theta^{2}\left(c_{b}-c_{g}\right)^{2} \frac{\theta-1}{(\theta+\delta-\theta \delta)^{2}}<0
$$

It is clear that the higher level of bias is, the lower the firm profit.

\section{Proof of Lemma 2}

Suppose bank 1 let the borrowing firm continue with bad cost report with probability $x$, and bank 2 does so with probability $y$. Then bank 1 should have the following program:

$$
\max x y \Pi_{c}\left(c_{b}, c_{b}\right)+x(1-y) \Pi_{m}\left(c_{b}\right)+(1-x) K
$$

Taking the first order condition, we have:

$$
\begin{aligned}
& \frac{\partial}{\partial x}\left(x y \Pi_{c}\left(c_{b}, c_{b}\right)+x(1-y) \Pi_{m}\left(c_{b}\right)+(1-x) K\right) \\
= & \Pi_{m}\left(c_{b}\right)-K+y \Pi_{c}\left(c_{b}, c_{b}\right)-y \Pi_{m}\left(c_{b}\right)=0
\end{aligned}
$$

Solving for $y$, we have:

$$
y=\frac{\Pi_{m}\left(c_{b}\right)-K}{\Pi_{m}\left(c_{b}\right)-\Pi_{c}\left(c_{b}, c_{b}\right)} .
$$

\section{Proof of Proposition 3}

The firms' expected profits under unbiased accounting system are

$$
\theta^{2} \Pi_{c}\left(c_{g}, c_{g}\right)+\theta(1-\theta) \Pi_{m}\left(c_{g}\right)-(I-K+\theta K) .
$$

The firms' expected profits under conservative accounting system are

$$
\theta^{2} \gamma^{2} \Pi_{c}\left(c_{g}, c_{g}\right)+\theta \gamma(1-\theta \gamma) \Pi_{m}\left(c_{g}\right)-(I-K+\theta \gamma K) .
$$


Taking the difference between these two expected profits, we have

$$
\begin{aligned}
& \theta^{2} \gamma^{2} \Pi_{c}\left(c_{g}, c_{g}\right)+\theta \gamma(1-\theta \gamma) \Pi_{m}\left(c_{g}\right)-(I-K+\theta \gamma K) \\
& -\left(\theta^{2} \Pi_{c}\left(c_{g}, c_{g}\right)+\theta(1-\theta) \Pi_{m}\left(c_{g}\right)-(I-K+\theta K)\right) \\
= & \theta(1-\gamma)\left((\theta+\theta \gamma)\left(\Pi_{m}\left(c_{g}\right)-\Pi_{c}\left(c_{g}, c_{g}\right)\right)-\left(\Pi_{m}\left(c_{g}\right)-K\right)\right) .
\end{aligned}
$$

We know $\Pi_{m}\left(c_{g}\right)=\frac{\left(a-c_{g}\right)^{2}}{4}>\Pi_{c}\left(c_{g}, c_{g}\right)=\frac{\left(a-c_{g}\right)^{2}}{9}>K$. Thus the above value will be strictly positive when $(\theta+\theta \gamma)\left(\Pi_{m}\left(c_{g}\right)-\Pi_{c}\left(c_{g}, c_{g}\right)\right)>\left(\Pi_{m}\left(c_{g}\right)-K\right)$.

\section{E Proof of Corollary 4}

We examine the change of the firm's profit in $\gamma$. Taking the partial derivative, we have

$$
\begin{aligned}
& \frac{\partial}{\partial \gamma}\left(\theta^{2} \gamma^{2} \Pi_{c}\left(c_{g}, c_{g}\right)+\theta \gamma(1-\theta \gamma) \Pi_{m}\left(c_{g}\right)-(I-K+\theta \gamma K)\right) \\
= & \theta\left(\left(\Pi_{m}\left(c_{g}\right)-K\right)+2 \theta \gamma\left(\Pi_{c}\left(c_{g}, c_{g}\right)-\Pi_{m}\left(c_{g}\right)\right)\right) .
\end{aligned}
$$

Clearly the firms' profits will increase in $\gamma$ if $\Pi_{m}\left(c_{g}\right)-K>2 \theta \gamma\left(\Pi_{m}\left(c_{g}\right)-\Pi_{c}\left(c_{g}, c_{g}\right)\right)$, which means less conservatism leads to higher profit. However, if $\Pi_{m}\left(c_{g}\right)-K<2 \theta \gamma\left(\Pi_{m}\left(c_{g}\right)-\Pi_{c}\left(c_{g}, c_{g}\right)\right)$, the firms' profits will decrease in $\gamma$, which means higher conservatism leads to higher profit.

\section{F Proof of Corollary 5}

Suppose the bank let the borrowing firm continue with probability $x$. Then it will have the following program:

$$
\begin{aligned}
& \max _{x} x y\left(\beta \Pi_{c}\left(c_{b} \widehat{c}_{b}, \widehat{c}_{b}\right)+(1-\beta) \Pi_{c}\left(c_{g}, \widehat{c}_{b}, \widehat{c}_{b}\right)\right) \\
& +x(1-y)\left(\beta \Pi_{m}\left(c_{b}\right)+(1-\beta) \Pi_{m}\left(c_{g}\right)\right)+(1-x) K
\end{aligned}
$$


Setting the $\mathrm{FOC}=0$ and solving for $y$, we obtain

$$
y=\frac{\beta \Pi_{m}\left(c_{b}\right)+(1-\beta) \Pi_{m}\left(c_{g}\right)-K}{\beta \Pi_{m}\left(c_{b}\right)+(1-\beta) \Pi_{m}\left(c_{g}\right)-\beta \Pi_{c}\left(c_{b}, \widehat{c}_{b}, \widehat{c}_{b}\right)+(1-\beta) \Pi_{c}\left(c_{g}, \widehat{c}_{b}, \widehat{c}_{b}\right)} .
$$

